\title{
ARTICLES
}

Submitted 10.08.2015. Approved 02.05.2016

Evaluated by double blind review process. Scientific Editor: Maria Ceci Araujo Misoczky

DOI: http://dx.doi.org/10.1590/So034-759020160306

\section{AMBIGUITY IN THE IDENTITY TRANSFORMATION OF PUBLIC HEALTH ORGANIZATIONS}

\author{
Ambiguidade na transformação da identidade de organizações públicas \\ de saúde
}

\author{
Ambigüedad en la transformación de identidad de organizaciones \\ públicas de salud
}

\section{EDUARDO ACUÑA}

eacuna@unegocios.cl

Professor at Universidad de Chile,

Facultad de Economía y Negocios -

Santiago, Chile

\section{MATIAS SANFUENTES}

msanfuentes@unegocios.cl

Professor at Universidad de Chile, Facultad de Economía y Negocios Santiago, Chile

\begin{abstract}
This study explores the transformations implemented by health authorities in a hospital over the last forty years with the purpose of institutionalizing geriatrics in the Chilean public health system. The transformations have been implemented through a process of identity conversion that had implied high levels of ambiguity due to the contradictory coexistence of the old hospital's identity with the new geriatric practices. These ambiguities are associated with the erratic, precarious support provided by state authorities to the development of the public geriatric framework. Through the handling of images, authorities have paradoxically amplified the achievements of these transformations, thus promoting apparent complacency in internal and external audiences.
\end{abstract}

KEYWORDS | Ambiguity, identity, change, history, organizations.

\section{RESUMO}

Este estudo explora as transformações implementadas por autoridades de saúde em um hospital durante os últimos quarenta anos, com a finalidade de institucionalizar a geriatria no sistema de saúde pública chilena. As transformações foram implementadas por meio de um processo de conversão de identidade que implicou altos níveis de ambiguidade, devido à existência contraditória da identidade do antigo hospital com as novas práticas geriátricas. Estas ambiguidades são associadas ao apoio errático e precário fornecido pelas autoridades do Estado ao desenvolvimento da estrutura geriátrica pública. Através da manipulação de imagens, as autoridades paradoxalmente ampliaram as conquistas destas transformações, promovendo uma aparente complacência nos públicos interno e externo.

PALAVRAS-CHAVE | Ambiguidade, identidade, mudança, história, organizações.

\section{RESUMEN}

Este estudio explora las transformaciones implementadas en los últimos cuarenta años en un hospital por autoridades de salud con el propósito de institucionalizar la geriatría en el sistema público de salud chilena. Las transformaciones han sido llevadas a cabo a través de un proceso de conversión de identidad que ha implicado altos niveles de ambigüedad debido a la contradictoria coexistencia de la antigua identidad del hospital con las nuevas prácticas en geriatría. Estas ambigüedades están asociadas a un errático y precario apoyo brindado por las autoridades de salud en el desarrollo de una institucionalidad geriátrica. A través del manejo de imágenes, las autoridades han amplificado paradójicamente los logros de estas transformaciones, promoviendo así una aparente complacencia en audiencias internas y externas.

PALABRAS CLAVE / Ambigüedad, identidad, cambio, historia, organizaciones. 


\section{INTRODUCTION}

This article is based on a study conducted in a Chilean public hospital that has experienced discontinuous incremental transformations in its organizational identity over the last forty years. The study analyzes the history of the process of identity conversion (Hall, 2010; Mahoney \& Thelen, 2010) from a hospice into a public geriatric hospital. Significant changes have been made in an effort to replace the hospital's old identity with the new organizational structure, a process in which the institution has become today's National Geriatric Institute (NGI). This case is of interest because the institutional transformations have generated high levels of ambiguity due to the conflictive coexistence of the hospice with the geriatric identity (Sanfuentes \& Acuña, 2014). Several pieces of evidence suggest that the NGI has an ambiguous identity, which is a source of stress and confusion for both internal and external audiences (Feldman, 1991; Martin, 1992; Meyerson, 1991).

The study highlights the relevance of ambiguity in strategy and identity changes brought about by the work of managers in contemporary organizations (Alvesson, 1990, 2013; Alvesson, Ascraft, \& Thomas, 2008; Alvesson \& Sveningsson, 2003; Gioia, Price, Hamilton, \& Thomas, 2010; Hoggett, 2006; McCabe, 2009). Ambiguity is linked to complex hierarchical relationships, imprecise goals, confusing result assessments, and unstable political support from authorities. The emergence of such phenomena is more intense in service organizations, public hospitals, universities, professional groups, government advisories, and businesses that make an intensive use of knowledge (Alvesson \& Sveningsson, 2003; Denis, Langley, \& Cazale, 1996; Gioia \& Chittipeddi, 1991; Feldman, 1991; Meyerson, 1991; McCabe, 2009). Ambiguity often leads to amplifying conflicts and resistance, since the lack of clarity in the diverse interpretations causes people to feel disoriented, manipulated and distrustful (Feldman, 1991; Hoggett, 2006; Martin, 1992; Meyerson, 1991). Organizations try to impose limits to ambiguity in order to avoid chaotic situations or serious misunderstanding. This leads to the creation of cultural formulations of "metameanings" that aim to neutralize inconsistencies while giving them a positive spin and the flexibility to handle identities that may display different values and meanings (Alvesson, 2003).

This study originated with a research strategy ethnographic inspired that the authors conducted at the NGI. That approach allowed us to become familiar with the organizational life and modernizing actions that have brought the NGI to its present identity as a leading geriatric institution in the Chilean public healthcare system. The research also enabled us to adopt a critical distance in order to examine NGl's institutional achievements.
Through a combination of closeness and critical distance, we were able to see through the obvious presented by institutional barriers and to access evidence of the institutionally ambiguous, contradictory aspects of NGI's identity. The contradictions we observed led us to investigate the history of NGl's transformations in order to understand the way in which past human actions and social processes have influenced the development of NGI's present identity as a public health institution.

The purpose of this paper is to examine the phenomenon of ambiguity in the context of the spatial, historical, and political changes experienced by the NGI and Chilean society in recent decades (Alvesson et al., 2008; Rowlinson, Jacques, \& Booth, 2009). This study delves into the various forms that ambiguity may assume in the different stages of an identity conversion process. It also explores the organizational strategies that allow keeping a public health institution functioning under high levels of ambiguity. Historical institutionalism, constructivism, and hermeneutics are the main theoretical perspectives employed in this study (Alvesson, 2013; Alvesson et al., 2008; Boje, 2001; Dutton \& Dukerich, 1991; Ravasi \& Schultz, 2006; Suddaby, Foster, \& Mills, 2014).

What follows below is the presentation of a theoretical framework that allows understanding the institutional changes in NGI's identity and the ambiguities associated with these changes. We then present a description of the study and the main methods we used in order to gather and analyze data. After that, we present the study's primary findings. Finally, we close the study with a critical discussion about its results.

\section{THEORETICAL ASPECTS}

\section{Changes in organizational identity}

Conditioned by the political context and institutional characteristics, transformations in the identity of an organization can follow radical, abrupt change strategies, or they can take place through an incremental, intermittent change process. For the purposes of this study, we highlight changes due to conversion, by which we mean the intervention of opportunistic political coalitions to carry out progressive, intermittent alterations in order to modify an identity that is formally institutionalized in an existing organization (Mahoney \& Thellen, 2010). By deploying a new interpretive framework, the coalition conducts the conversion of a given institution and creates for this institution a renewed identity that is expressed in new functions and purposes. In some cases, the conversion results in adding new supporters to the organization. In the case of a new political coalition that 
takes over power, instead of dismantling the former organization, the coalition will use it in an innovative way by exploiting the ambiguities found within the system (Scott, 2014; Selznick, 1957). In order to advance and consolidate innovations in the conversion process, it is vital for the dominant political coalition to acquire and maintain legitimacy with both internal and external audiences (Mahoney \& Thellen, 2010). This presupposes expanding the management of legitimacy through the combination of various strategies, pragmatics, morals and symbols that depend on circumstances, audiences and interests (Clegg, Rhodes, \& Kornberger, 2007; Kroezen \& Heugens, 2013; Suchman, 1995).

\section{State, institutions and legitimacy}

The state plays an essential political role in the achievement of legitimacy, due to its participation in the development, maintenance and reconstruction of contexts and institutional arrangements. This constitutes a social, economic and political order rooted in particular norms, values and expected behaviors (Bucheli \& Kim, 2014; Weber, 2009). The state is developed through the participation of heterogeneous groups that compete for economic resources as well as values and norms. Their degree of legitimacy and political support depends on the outcomes of this process. Public and private organizations determine their legitimacy according to the order established by the state, and deploy strategies to influence governmental decisions on the formulation and reformulation of the "rules of the game" to justify their interests. The state is founded in a political history that influences which social actors can have access to control, what interests are given priority, and what kind of institutional framework is built, including the possibility of changing the very nature of the state's institutional framework. These changes acquire greater legitimacy when they are implemented within institutions than when they are externally imposed. Likewise, the interests these changes represent affect the legitimacy of the changes themselves. Therefore, changes are strengthened when aligned with socially shared interests, and weakened when the interests represent only elite groups.

The legitimacy of the state, its institutions and the policies implemented in a specific society are affected by how leaders rise to power, whether by clean or fraudulent elections or coups d'état. This legitimacy is also affected by those who support the government before and during its administration period (majorities and minorities). Access to power through the use of force is often a dramatic event that brings with it radical institutional changes. Such changes destroy the legitimacy of the prior social order and replace it with new institutions and institutional arrangements, the legitimacy of which is affected by how much support these arrangements receive from citizens. When a de facto government maintains power solely with the support of minorities, the government's central task becomes to exercise an ironclad control over the majority of the population to avoid resistance and emancipatory measures (Moulian, 1997; Salazar \& Pinto, 1999; Walker, 2003).

\section{Organizations and ambiguity}

Ambiguity enshrouds the life of an organization during the period when it is defining its policies and changing its strategy and identity. We subscribe to Feldman's (1991) definition according to which "ambiguity occurs when there is no clear interpretation of a phenomenon or set of events. It is different from uncertainty in that it cannot be clarified by gathering more facts. The facts that are or could be available support more than one interpretation" (Feldman, 1991, p. 146). Baier, March, and Saetren (1988) examine ambiguity in the implementation of public policies under the complexity of bureaucratic relationships. The formulation of public policies becomes ambiguous when central agencies establish imprecise and/or hard-to-meet goals, failing to clearly anticipate the necessary resources for implementation, the essential coordination between organizations, the political interests at stake, and incentives for achieving results. The authors emphasize the paradoxical effect of ambiguity on the adoption and maintenance of public policies in situations that combine the support of a wide coalition of actors who somehow feel they have a stake in the process.

McCabe (2009) examines the construction of strategies and shows how managers can use their power in an ambiguous, contradictory way, and how this can confuse change efforts once resistance develops in the face of transformations. Managing strategies requires ambiguity to be suppressed in favor of a dominant set of values, beliefs and interpretations. Ambiguity is also critical for the exercise of power as they allow proposals to be included in strategies without any indication on how such proposals are to be implemented, even though they require interpretation. Ambiguity allows the use of multiple interpretations, which can give rise to a diversified entity where people believe that their interests will be satisfied through diversification. Ambiguity has the potential to amplify conflicts and resistance because individuals can interpret a situation and act on it in a number different of ways. Individuals can also feel very frustrated due to a lack of clarity, which may cause feelings of manipulation and distrust (Alvesson, 2013; Feldman, 1991; Hoggett, 2006). 


\section{Images, identity and ambiguity}

The construction of images and ambiguities has been the subject of studies as part of the organizational identity, within a context of reciprocal interactions and influences between organizations' internal and external audiences. Alvesson $(1990,2013)$ suggests that the images are connected with the visions and ideas that organizations create with the purpose of influencing audiences' impressions and attitudes about them. These images are inevitably ambiguous, lingering between the imagination and the senses, and between expectations and reality. These images are not necessarily false. The challenge facing organizations is to create an image that can ensure people that a certain type of impression is credible. The creation and management of imagery within modern organizations is of particular importance considering the cultural changes, the increasing complexity and turbulence experienced in social environments, the heightened role of mass communication, the development of the service sector, and increasing demands for quality. These changes have resulted in societal contexts filled with symbolic representations that encourage organizations to compete by using their images, which have become powerful and plausible, if sometimes false, in order to leave lasting impressions. This competition using mass media means that organizations frequently create manipulative events, actions and structures to impress audiences by using the images they project. Under such competitive circumstances, the question arises of whether these symbolic representations and changes are actually integrated with organizations' identities or only superficial, cosmetic fixes.

Gioia, Schultz, and Corley (2000) sustain that organizational identity is affected by the instability of volatile environments, leading organizations to make adaptations in their identities. The authors affirm that, as a tactic to allow identity changes, organization members deliberately insert ambiguity into the original concepts of the organization's nature. This can produce the instability of interpretation necessary to create opportunities that allow changing aspects of identity. "When the senior management engenders 'ambiguity by design' they tend to destabilize existing interpretations and to create a desire for resolving the ambiguity" (Gioia et al., 2000, p. 361). With the fluidity of post-industrial societies, the creation of organizational images is an adaptive resource often used to counteract instability. However, when these images only deal with the handling of impressions, their nature becomes too transitory and fragile to define identity.

\section{Territory, identity and ambiguity}

The material side of organizations, including its territory, architecture and spatial arrangements, plays an important role in organizational identity and the experiences of ambiguity. Using a socio-technical and functionalist perspective, Miller (1983) highlights the fundamental role played by the design and management of boundaries and territories for organizational effectiveness. This management includes developing identity in units and groups, based on specific aspects of technical tasks, the spatiality of work, and time horizons. All these elements have implications for the effectiveness of tasks and the cohesion and commitment of individuals. Dysfunctional boundary design and management can be the source of ambiguity as it confuses the affiliation of individuals within groups, and the overlapping of duties between groups dilutes responsibilities and accountability. Ambiguity also emerges when collaboration between groups is weak, or when antagonistic or competitive relationships prevail.

Burrel and Dale (2003) analyze the role that space and architectural design have on management and organizations, particularly when they are expressions of political power in the elaboration of identities, behaviors and representations meant for organizational members and consumers. Planners, scientists, politicians, managers and architects deliberately design and build organizational spaces in such a way as to enable functionality for both productive and administrative activities within organizations. In addition to this, there is the manner in which the space is represented, developing symbolic, aesthetic and phantasmagoric qualities that strongly influence the subjectivity of individuals. Anesthetic effects are attributed to the handling of symbolic and aesthetic aspects of the corporate space. These effects can darken and transform the conditions of use underlying the organization of production in such a way that people become accustomed to it. The authors affirm the possibility of creating emancipatory structures and spaces that express democracy, transparency and openness in such a way that the ambiguities implicit in the structural design of organizations can be challenged.

Martin (1992) adopts the perspective of cultural fragmentation to refer to the symbolic ambiguity that occurs when the values associated with egalitarianism do not seem to have a clear relationship with the spatial arrangements of open offices where individuals in higher hierarchic positions appropriate spaces while those of lesser rank must accommodate themselves according to the space available. Spatial arrangements are also a matter of ambiguity regarding the effectiveness that can be achieved by working in open offices. Some interpretations suggest that these spaces aid productivity, while others warn that shared office spaces permit social relationships that promote a lack of focus on tasks. 


\section{METHODOLOGY}

This article was based on an interpretative ethnographic study conducted by a team of native Chilean researchers led by the authors of this paper in three stages over a twelve-month period. In the first phase, fieldwork focused on examining the workers' experiences of stress and burnout. In the second phase, the organization's history and memory, from the hospice days to the present, were explored. The third phase focused on inquiring about the transformations in NGI's organizational identity throughout its history, as well as the impacts of such transformations on the organizational life. Phases one and two provided an interpretive understanding of the institution's identity changes. Both phases provided a socio-historical framework for members' subjective experiences and memories at the NGI. These phases constitute platforms upon which the present study develops new, comprehensive interpretations to examine the transformations in NGl's identity (Acuña \& Sanfuentes, 2011; Kipping, Wadhwani, \& Bucheli, 2014; Sanfuentes \& Acuña, 2014).

In the third phase, we used in-depth interviews that enabled learning about NGl's primary milestones throughout its history. Ten NGI members were interviewed. They had full or partial knowledge of the transformations due to their positions of authority, professional responsibilities, and seniority in the organization, and were able to provide pluralistic and complementary views of the changes. The number of interviews was determined by fact that these ten people were the ones with largest experience involving the institution's identity transformations. The interviewees were: NGl's current chiefdirector, who has been a direct protagonist in the transformations since the hospice period; the institution's medical and administrative deputy directors, who have spearheaded changes and faced resistance in their respective areas over the past fifteen years; three doctors, two of whom were working at the organization during the hospice period and have remained at the $\mathrm{NGI}$, and a doctor who has been working at the NGI for more than fifteen years; three union leaders with knowledge of the latest $\mathrm{NGI}$ changes and their impact on workers; finally, an interview was held with a former NGI assistant who worked at the hospice.

The interviews were conducted as a dialogic conversation where respondents gave information about their perceptions and experiences regarding NGl's changes. All the interviews were recorded using audio-recording devices and were later transcribed. The NGI chief-director was interviewed on five occasions because of her expertise and direct knowledge of the institution's transformations since its hospice period until the present. All interviews with her were conducted with a team of three interviewers in order to make data collection more effective.
After each interview, the team of interviewers held reflection meetings to evaluate the data and prepare new interviews (Alvesson \& Sköldberg, 2004; Hoggett, 2013). In each interview, we used critical hermeneutics to interpret the emerging contents, which implied that the interviewers were aware of their own mental processes, as well as the meanings communicated by the interviewee. The team made every effort to be insightful enough to understand the unconscious communications in the interview dynamics (Alexandrov, 2009). The interviewers encouraged the respondents to recount their personal stories or narratives about the identity transformations that took place at the NGI.

After the transcription phase, each of the interviews was examined using the hermeneutic narrative method, which involves unveiling the story's script and its meaning with regard to NGI's identity transformations (Czarniawska, 2004; Ricoeur, 1981). This meant that the director's narrative was particularly important because it revealed a plot that is the backbone of the full chronology of NGI's identity-transforming events and their social and historical circumstances (Ricoeur, 2004). We consider the text originated by the director as the story arc of this identity transformation, a storyline in which the other interviewees' narratives fit in and reinforce the meanings of the greater framework. By studying each narrative, we were able to weave a comprehensive interpretation of these transformations, thus producing a chronological and textual coherence that differentiates the transforming events that have occurred up to the present.

The methodology also included the study of secondary information related with the hospice's history and Chile's contemporary society. The validity of this study's interpretations is corroborated by the internal consistency between each narrative and the conceptual theme, between the stories themselves, and between the narratives and the secondary data. We consider the content saturation in the interpretations as proof of validity.

\section{PRINCIPAL FINDINGS: CONVERSION, TRANSFORMATION AND AMBIGUITY}

\section{Ambiguity in the incorporation of the hospice into the public health system}

The Santiago Hospice was founded in 1759 and officially ceased to exist in 1976 when health authorities recreated it as the Geriatric Center. Since its start, the hospice suffered from complex, precarious conditions, both in economic and administrative terms, which resulted in various closures and restarts. The hospice was run by members of the Chilean upper class and Catholic clergy 
who, for philanthropic reasons, dedicated themselves to helping the destitute. At the hospice, the life of residents was regulated by a system of disciplinary confinement that sought to plant the seed of ethical work in order to correct the "bad habits of poverty". The hospice received no government support for its survival (Laval, 1938; Montauban, 1887; Silva, 2007).

This situation continued until 1968, when the government decided to expropriate the land where the hospice was located due to urban reforms that were underway. As a result, Chilean health authorities incorporated the hospice into the National Health Service, which then became responsible for the institution's residents. This meant transferring groups of patients to psychiatric hospitals. The majority of residents were sent to another establishment where the hospice would be transferred to, which is also where the NGI is now located. Before this, the facilities had housed a dermatologic hospital. After a few years coexisting with the hospice, the dermatologic hospital was relocated to integrate a nearby general hospital. Thus, in its new location, the hospice assumed the condition of a public health organization; however, this did not result in substantial improvements to its main function of providing care for the residents.

It is worth highlighting the ambiguous nature of the hospice's incorporation into the National Health Service, since this was not a decision that followed healthcare policies; in fact, the decision followed governmental purposes related with Santiago's urban development. Nevertheless, the incorporation raised the assumption that the hospice would receive government support to improve the treatment of residents, in line with the institution's new identity as a public health organization. Instead, history shows that the hospice's institutional precariousness continued inertially the same, with health care for residents remaining minimal. Over the years, ambiguity about the hospice's incorporation has persisted on the part of Chilean health authorities, for whom the state took on a heavy burden that used to be the responsibility of private charities (Baier et al., 1988; Bucheli \& Kim, 2014; Jocelyn-Holt, 2014).

\section{Dictatorship, conversion, transformations and ambiguity}

\section{Ambiguity in the creation of the geriatric center}

In the early phase of the Chilean dictatorship (1973-1989), more specifically in 1976, the country's health authorities decided to close the hospice by means of an institutional conversion that turned it into the Geriatric Center (Salazar \& Pinto, 1999). Having realized that an increasing part of the Chilean population was aging, the authorities thought that the hospice's institutional framework was appropriate for turning it into a service dedicated to elderly care (Hall, 2010; Mahoney \& Thelen, 2010). In order to build the Geriatric Center, the authorities opportunistically took advantage of the Hospice's legal and financial status, which remained ambiguous as its structure and functionality were neither dissolved nor strengthened. The conversion momentum initiated by the government eventually died out, resulting in a stalled project until the present - and for years to come - since it was not governmental priority. In addition, the center never had access to any technical expertise in order to guide the process. Thus the creation of the Geriatric Center was enveloped in ambiguity from its very beginning. The institution officially exists but has no means to achieve its goals. As a result, the hospice continues to function according to its old patterns, i.e. a place of homeless seclusion (Alvesson, 1990; Baier et al., 1988).

\section{Ambiguity, beginnings and development of the geriatric identity}

In 1983, the project of the Geriatric Center had its foundation strengthened when it hired a young doctor who had studied geriatrics in Spain. She, the hospice director and two attending physicians created a political coalition that managed to lay the foundations of the institution's geriatric identity (Hall, 2010; Mahoney \& Thelen, 2010). This coalition embraced the young doctor's proposal to create an elderly rehabilitation model that did not include lifetime internment of patients. By using specific treatments, they would be reintegrated into their families and community. Patients' families, doctors from other hospitals and authorities agreed with the initiative in general, but opposed the Center's focus on reducing patients' stay to short periods (Gioia \& Chittepeddi, 1991; Gioia et al., 2010). Under these terms, the opposition agreed with the rehabilitation model (Suchman, 1995). This meant that, at an early stage, the conversion towards the geriatric identity would adjust to the hospice's old institutional framework, which contributed to form the nucleus of ambiguity that muddled the real purpose of transformations.

Given these advances towards the geriatric identity, in 1984, the Health Ministry officially recognized the Center as a public entity specialized in elderly care. This implied making the Center's institutional hierarchy official, allowing it access to ministerial decision-making, larger financial resources and a more numerous staff. In spite of this legitimacy, ministerial authorities continued ambivalent on how they viewed the Center. On the one hand, they appreciated the inclusion of geriatrics in the public healthcare system, while, on the other, they criticized the low productivity at high costs that this service required 
compared to the hospice. The Center's dominant coalition knew how to take political advantage of authorities' ambivalence to progressively legitimize the geriatric identity. At the time, the Center's management was working on such a tight budget that they were not able to acquire basic resources such as an intensive care ward, an exam laboratory, or an ambulance.

The exploitation of ambiguities in the hospice's institutional framework also included measures to ensure that the employees who kept their jobs could adapt to the institution's new geriatric duties. This meant that the previous patterns of abuse of authority inflicted on patients had to stop. Compliance with work duties was solidified; employees had to obey medical authorities and participate in training programs for the new work. Furthermore, the Center's dominant coalition firmly rejected actions taken by anonymous health authorities, who tried to destroy the advances towards the geriatric identity by privatizing the Center. They also managed to protect the Center from a failed attempt at selling the Center's premises to generate income to repay debts of the Healthcare Service (Clegg et al., 2007; Denis et al., 1996).

Until 1989, the Center's dominant coalition was increasingly strengthening its legitimacy and achievements in terms of geriatric identity in the eyes of the Health Ministry. However, two major political events occurred in this period that affected the stability of the institution. One was the death of the Center's chief-director, who, as a doctor and a military, had been an extremely important aid to develop the geriatric identity by taking advantage of the ambiguity inherent in the hospice's institutional framework. The doctor who had promoted the rehabilitation model took over as the new chief-director. Her priority was to join forces with the other doctors at the Center to create a political alliance that would consolidate the achievements made in the geriatric identity both for dealing with internal and external audiences. This alliance also tried to anticipate how the Center would be affected by Chile's imminent transition from Pinochet's 17-year long dictatorship to a democratic regime. These two events meant that an atmosphere of consolidation and political realignment regarding future conditions would be predominant at the Center (Moulian, 1997; Suchman, 1995).

\section{The return of democracy, ambiguity and transformation}

With the return of democracy in 1990, the Center's directors began to maneuver in order to position the organization as the focal point of elderly health care policies in the new democratic governments (Denis et al., 1996; Gioia et al., 2010). In 1995, the Center designed and launched a comprehensive geriatric service program for the treatment, rehabilitation and social reintegration of senior adults. Additionally, administrative changes were made in order to support modifications in clinical treatments. Such changes were in line with health reforms promoted by the central government which emphasized achieving goals of efficiency and quality (Artaza, 2004). In 1996, the NGI's directors joined efforts to convince the government to create the National Service for Senior Citizens (SENAMA), thus putting elderly care under the control of the nation's public institutions. Due to the increasing influence the Center and its leadership had on the government at the time, in 1997, the Ministry of Health raised the Center to the status of NGI. This new identity was meant to endow the organization with the necessary expertise, infrastructure and human resources for a complex variety of initiatives: efficiently responding to increasing pressures for healthcare needs; being a national model for geriatric healthcare practices throughout the nation; assisting in training geriatric specialists; and conducting research. The NGI also had to assimilate the practices set forth in the New Public Management to achieve higher levels of efficiency and productivity (Gioia et al., 2010; Hall, 2010).

The status of National Geriatric Institute was the summit of the former hospice's identity conversion process. However, due to NGl's roots in the hospice's institutional framework, the conversion brought along ambiguities that overshadowed this new identity. The NGI had complex tasks, but achieved inconsistent results due to insufficient resources. The infrastructure and facilities were virtually the same as in the hospice period. NGI's funds, which came primarily from the Ministry of Health, were insufficient to cover the institution's multiple projects.

In addition, ambiguity remained with regard to the admission of patients requiring long-term stay. These cases contradicted NGl's policies of rehabilitation and support for the families, and affected the institution's budgetary balance due to noncompliance with the Ministry's productivity indices, which were based on the number of hospitalization days. An additional difficulty was the strict control the central government exercised concerning compliance with productivity goals. These goals placed an increased burden on the NGI staff by making it difficult to reconcile compliance demands with quality service to patients. Licensed staff members in particular had difficulties to adjust to the ministry's metrics, according to which goal-meeting performance was rewarded and inefficiency penalized (Alvesson, 1990; Baier et al., 1988; Hall, 2010).

\section{Transformations, spatiality and ambiguity}

The transformation of NGI's identity has occurred within the same spatial and territorial context, having fully preserved the decaying, nineteenth-century character of the buildings, offices and clinical 
wards. Such lack of real changes contrasts strongly with NGI's official discourse, which emphasized a modern conception of public healthcare service, particularly regarding clinical and administrative advances. The temporal-spatial ambiguity is disconcerting for NGI members. On one hand, they work in a physical space that refers to an unknown past; on the other, they hear a progressive medical discourse according to which the institution can supposedly face the present and future challenges in national geriatric healthcare.

The ambiguity that arises from the physical environment is markedly influenced by structures that were designed and built in the nineteenth-century to serve as a place of withdrawal for the Jesuits, meaning that the place's infrastructure is notoriously dysfunctional to provide healthcare services to elderly patients (Miller, 1983). The ambiguity connected to the spatiality is also expressed in the anonymous nature of NGl's public identity, which is unknown to the majority of citizens as well as to other healthcare professionals. This anonymity results from the almost complete lack of signage on the organization's façade. This is in sharp contrast with the visibility that other hospitals in the area have. For those who work at the NGI, the place is portrayed as if it had a fictional quality, like a place frozen in time. The unawareness of the existence of the NGI could perhaps be indicative of the diminished esteem that the Healthcare System has for this organization (Burrel \& Dale, 2003; Sanfuentes \& Acuña, 2014).

Additionally, this spatiality plays a dramatic role in the ambiguity of NGI's identity as a result of the strong earthquake that shook the central region of Chile in 2010. It destroyed a substantial number of the old buildings, while leaving others at serious risk of collapse. This prompted the Ministry of Health to shut down the NGI (Miller, 1983). NGI's directors and workers resisted the closure and proposed to the Ministry for the basic clinical wards to be repaired. The NGI was allowed to continue operating within a section of the nearest general hospital, where NGI staff could treat the patients with greatest necessity of care. The Ministry's authorities accepted the proposal and the NGI continued functioning in that hospital for two years. This meant that the visibility of NGI's clinical work dissipated in another location, intensifying the ambiguity about its identity and existence. NGI's directors and staff had to concentrate efforts to counter this ambiguity and show that, despite their being physically present in another location, the institution's geriatric identity continued to exist.

After two years at the general hospital, the NGI returned to its old place, where some of the structures damaged by the earthquake had been rebuilt (Miller, 1983; Ravasi \& Shultz, 2006). The reinstallation kept the institution's high level of ambiguity, as the NGI reduced its operations to only a small number of hospital beds in addition to outpatient services. NGl's precarious, unstable survival barely kept it from being shut down as a public health organization. The ambiguity about NGl's identity remains because, in the eyes of the Ministry's authorities, its operations are expensive and of low productivity compared with other public hospitals. Nevertheless, in collective imagination, NGl's sustainability remains alive, particularly due to hopes that a new hospital will be built. This has been an unfulfilled promise in successive Chilean government administrations who have postponed a rational solution to the problem of the aging population (El Mercurio, 2014).

\section{DISCUSSION}

This study is characterized by approaching NGI's identity changes based on the institutional, constructivist and historical perspectives in order to enrich the analysis of data. It is worth stressing that the process of constructing the geriatric identity is deeply based on incremental, intermittent institutional changes that have been carried out over time. Health authorities adopted an opportunistic stance and used a conversion strategy on the hospice's institutional framework to create the geriatric identity. They took advantage of the hospice's institutional, spatial and human capital to ensure that the changes were accelerated (Hall, 2010; Mahoney \& Thelen, 2010). Nevertheless, the conversion ended up being a long, complicated process since using the hospice's institutional framework meant dealing with high degrees of ambiguity and contradiction (Baier et al., 1988; Gioia et al., 2010; Ravasi \& Shultz, 2006).

Understanding the historical context allowed situating the conversion process within a framework that includes the hospice's past, the changes experienced by the Chilean society and the political role of the state (Bucheli \& Kim, 2014; Moulian, 1997; Salazar \& Pinto, 1999; Suddaby et al., 2014). Throughout the dictatorship and during the democratic regime, the state's influence has strongly impacted the geriatric identity even though governmental support to this identity has been erratic, precarious and intermittent considering the scope of the project.

The dominant political coalitions that have taken on the role of guiding the conversion, first at the Geriatric Center and later at the NGI, have been fundamental in consolidating the geriatric identity. The power of these coalitions stems from their technical expertise in implementing the current elderly treatment and rehabilitation methods, as well as their resilience and flexibility to overcome restrictions and questioning by the central government concerning the efficiency of geriatric care. Therefore, the identity conversion has been progressively constructed in a 
dynamic interaction between ministerial authorities and internal coalitions. NGl's current chief director has played an essential role throughout this process. From the very beginning, she has led the creation of the geriatric institution in the Chilean public healthcare system. The maintenance of this leadership over time has meant the continued existence of learning cycles. This director has been able to constructively handle the conflicts and problems that have emerged over the process because she is closely familiar with the institution's history. Her leadership resembles that of a stateswoman (Selznick, 1957) given the way her work surpasses a technical orientation geared towards rational goal achievement, favoring the organization's institutional development through the vicissitudes that envelop the conversion process (Gioia \& Chittipeddi, 1991; Suchman, 1995).

This study has allowed the deconstruction of NGl's identity, thus questioning the reification of its social order, which seemed to be rooted in some linear progression of modern medicine but lacked the central role played by history and social agencies in the construction of institutional reality. Using the study's historic depth, this deconstruction uncovers a genealogical identity of the NGI that refers to the obscure past of the old hospice. Since its foundation, it was a place of mass confinement for people living under poverty conditions. These conditions persisted even after the dictatorial government decided to create the Geriatric Center in 1976. The theoretical creation of the Center allowed to keep the hospice functionally alive. The subsequent transformations allowed putting an end to the dark, penurious past of the hospice. Nevertheless, this history of poverty, negligence and institutional discrimination resonates indelibly in the ambivalent, precarious support that successive government administrations of various ideologies have dedicated to geriatric healthcare in Chile.

The course that the institutionalization of the geriatric identity has followed is wrapped in a feigned grandiose project that has no relation with the scarcity of resources the organization suffers from. The utmost level of precariousness experienced by the NGI came after the devastation caused by the earthquake. But the feigned high-minded purposes in contrast with the precariousness of resources still create a level of ambiguity that is extremely tiresome to NGI members. This is a direct result of the irrational way in which health authorities made decisions to convert the hospice into a geriatric institution. Over the long term, this considerable ambiguity seems to embody an almost hopeless institutional inertia, given the governmental negligence, making it virtually impossible for a radical change to take place that might bring a new institutional situation for the NGI.

We believe that the methodology employed in this study has been fruitful because it enabled a combined exploration of the NGI and Chilean society's history. This allowed a better understanding of the dynamics between the key political actors in the geriatric identity conversion process. In this respect, it was extremely valuable to follow the methodological proposals of old institutionalism, which postulates the relevance of digging into the history of organizations in order to understand how they become institutions through internal and external dynamics (Scott, 2014; Selznick, 1957). These arguments show that institutional development implies transcending the strict lens of instrumental rationality for the achievement of goals. On the contrary, leaders should consider the political dynamics of the external context in order to preserve or adapt the organization's distinctive identity. The use of the narrative method through the analysis of the interviews conducted with NGI members familiar with its history, particularly the institute's chief director, provided the backbone of a realistic, plausible plot for the identity conversion. Furthermore, the use of the ethnographic method, which included observations and records of the NGl's physical and cultural environment, provided complementary evidence that validated the historical accounts of interviewees. The critical hermeneutic interpretation was indispensable for articulating a global understanding of NGI's history and transformations. Critical reflexivity was instrumental in ensuring the submission of evidence to tests of deconstruction that brought new interpretive meanings.

\section{CONCLUSIONS}

This article delves into the understanding of NGl's ambiguous identity, a situation caused by the contradictory coexistence of elements of the old hospice with the new geriatric healthcare approach. This coexistence has brought about confusion and conflicts to NGI's internal and external audiences regarding the institution's identity and the nature of its primary tasks and purposes. The study also explains how that ambiguity is rooted in a history of unreflected institutional transformations meant to convert the hospice's identity into that of a geriatric hospital. The use of a conversion strategy to create, maintain and develop the new identity has been subjected to the exploitation of ambiguities associated with the hospice's resources, traditions, territory, legal status, and organizational conditions. These elements have imposed strong limitations concerning the institution's autonomy and rationality of resources to consistently accomplish the magnitude of the transformative project.

This study stresses the key role of central government health authorities and the NGI's internal coalitions in the identity transformation process. Both at the Geriatric Center and at the NGI, these actors gradually responded through different initiatives to the development of the geriatric identity, in accordance with the 
ambiguous nature of the hospice's legacy. It is worth noting that the central government authorities have been predominant over the Institution's internal coalitions. While the former have acted autonomously and with power of veto, the latter have had a low level of discretion to manage its own institutional transformations. This political unbalance has led the internal coalitions to exert their authority both opportunistically and cautiously, thus taking advantage of the system's ambiguity. Such ambiguity has opened spaces for incremental, intermittent progress in the development of the geriatric institutional framework, whenever health authorities empowered changes (Alvesson et al., 2008; Mahoney \& Thelen, 2010).

This paper also describes how the evolution of Chilean society's historical and political context has decisively influenced the development of NGl's identity. Over the last forty years, democratic and authoritarian regimes have caused different effects on the institution's development. The military dictatorship encouraged the creation of the Geriatric Center, thus establishing a basic structure and economic resources to create a public healthcare system for the elderly. With the return of democracy, successive administrations opened new possibilities to create a strategic role for the Geriatric Center by giving it the status of National Geriatric Institute. As such, the NGI accomplished new, complex tasks and adapted its operations to the demanding standards of the new public management applied to the health system. These new responsibilities led health authorities to believe that the institutional framework had been radically changed into the geriatric model, leaving behind the hospice's legacy. However, we claim that such assumptions of superlative transformations are disproportionate in view of NGl's institutional and spatial precariousness and ambiguity, in spite of the evident achievements of its public geriatric healthcare approach (Alvesson, 1990, 2013).

The NGI has been able to survive over the years due to its capacity to face the ambiguity of successive transformations and to keep a hybrid character that contains aspects from different development stages. Such ambiguity is expressed in NGI's daily work through the actions of its employees and managers, the complexity of its tasks, and its ideological contradictions. The NGI has managed to maintain boundaries to avoid extreme uncertainty and chaos, which would make it impossible for the institution to survive. We claim that the ambiguous identity is kept by a tacit understanding between NGl's external and internal audiences, since the institution offers practical, technical, and ethical contributions to the well-being of the Chilean vulnerable elderly population. We also affirm that NGI's institutional legitimacy is rooted in this ambiguous identity that harbors a diversity of meanings that express the interests of various actors concerning the institution. Finally, we observe that the institutional leadership exerted by the NGI's chief director during the whole process of change has been a fundamental factor in managing high levels of ambiguity. By means of her skilled expertise and persuasiveness, she has been able to unite the institution and design a transcendent institutional sense, dealing with the manifest restrictions from the hospice's legacy. Influenced by the management team's leadership, NGl's health workers have assimilated a training and work mystique that enables them to cope with the challenges and dilemmas that emerge from the institution's ambiguous identity. That mystique is directly connected to NGI's historical genealogy, the hospice's centenary past, the authoritarian influences of the military regime, and the modernizing progress of the recent geriatric health approach (Alvesson, 2003; Martin, 1992).

\section{ACKNOWLEDGEMENTS}

This research was supported by Fondo Nacional de Investigación y Desarrollo en Salud - FONIS (CONICYT/ SA08120028) and Centro de Estudios de Conflicto y Cohesión Social - COES (CONICYT/FONDAP/15130009).

\section{REFERENCES}

Acuña, E., \& Sanfuentes, M. (2011). Institutional abuse: Caught between professional vocation and system's efficiency. In L. Gould, A. Lucey, \& L. Stapley (Eds.). The reflective citizen: Organizational and social dynamics (pp. 111-129). London, UK: Karnac.

Alexandrov, H. (2009). Experiencing knowledge: The vicissitudes of a research journey. In S. Clark, \& P. Hoggett (Eds.). Researching beneath the surface (pp. 29-49). London, UK: Karnac.

Alvesson, M. (1990). Organization: From substance to image? Organization Studies, 11(3), 373-394. doi:10.1177/017084069001100303

Alvesson, M. (2003). Understanding organizational culture. London, UK: Sage.

Alvesson, M. (2013). The triumph of emptiness consumption, higher education \& work organizations. Oxford, USA: Oxford University Press.

Alvesson, M., Ascraft, K., \& Thomas, R. (2008). Identity matters: Reflections on the construction of identity scholarship in organizations studies. Organization, 15(1), 5-28. doi:10.1177/1350508407084426

Alvesson, M., \& Sköldberg, K. (2004). Reflexive methodology. London, UK: Sage Publications.

Alvesson, M., \& Sveningsson, S. (2003). Good visions, bad micromanagement and ugly ambiguity: Contradictions of (non) leadership in a knowledge-intensive organization. Organization Studies, 24(6), 961-988. doi:10.1177/0170840603024006007 
Artaza, O. (2004). El contexto de los procesos de cambio en salud en distintos países de la región andina: El caso de Chile. En O. Artaza, F. Sacoto, A, Yglesias, L. Yáñez, F. Martínez, \& J. Torres-Goitia (Eds.), Reformas y financiamiento de sistemas de salud en la subregión andina (pp. 36-79). Lima, Peru: Organismo Andino de Salud.

Baier, V., March, J., \& Saetren, H. (1988). Implementation and ambiguity. In J. March (Ed.). Decisions and organizations (pp. 150-164). New York, EUA: Basil Blackwell.

Boje, D. M. (2001). Narrative methods for organizational \& communication research. London, UK: Sage Publications.

Bucheli, M., \& Kim, J. (2014). The state as historical construct in organization studies. In M. Buchelli, \& D. Wadhwami (Eds.). Organizations in time (pp. 241-262). Oxford, UK: Oxford University Press.

Burrel, G., \& Dale, K. (2003). Building better worlds? Arquitecture and critical management studies. In M. Alvesson, \& H. Willmott (Eds.). Studying management critically (pp. 177-196). London, UK: Sage.

Clegg, S., Rhodes, C., \& Kornberger, M. (2007). Desperately seeking legitimacy: Organizational identity and emerging industries. Organization Studies, 28(4), 495-513. doi:10.1177/0170840606067995

Czarniawska, B. (2004). Narratives in social science research. London, UK: Sage.

Denis, J., Langley, A., \& Cazale, L. (1996). Leadership and strategic change under ambiguity. Organization Studies, 17(4), 673-699. doi:10.1177/017084069601700406

Dutton, J., \& Dukerich, J. (1991). Keeping an eye on the mirror: Image and identity in organizational adaptation. Academy of Management Journal, 34(3), 517-554.

El Mercurio. (2014, 4 January). La eternal lucha contra los años del Instituto Geriátrico. Diario de Santiago, Santiago, Chile.

Feldman, M. (1991). The meanings of ambiguity: Learning from stories and metaphors. In P. Frost, L. Moore, M. Louis, C. Lundberg, \& J. Martin (Eds.), Reframing organizational culture (145-156). London, UK: Sage.

Gioia, D., \& Chittipeddi, K. (1991). Sensemaking and sensegiving in strategic change initiation. Strategic Management Journal, 12(6), 433-448. doi:10.1002/smj.4250120604

Gioia, D., Price, K., Hamilton, A. L., \& Thomas, J. (2010). Forging and identity: An insider-outsider study of processes involved in the formation of organizational identity. Administrative Science Quarterly, 55(1), 1-46. doi:10.2189/asqu.2010.55.1.1

Gioia, D., Schultz, M., \& Corley, K. (2000). Organizational identity, image and adaptative instability. Academy of Management Review, 25(1), 63-81.

Hall, P. (2010). Historical institutionalism in rationalist and sociological perspective. In J. Mahoney, \& K. Thelen (Eds.), Explaining institutional change ambiguity, agency and power (pp. 204-223). Cambridge, USA: Cambridge University Press.

Hoggett, P. (2006). Conflict, ambivalence, and the contested purpose of public organizations. Human Relations, 59(2), 175-194. doi:10.1177/0018726706062731

Hoggett, P. (2013). Haciendo investigación psicosocial. En E. Acuña, \& M. Sanfuentes (Eds.). Métodos socioanalíticos (pp. 59-78). Santiago, Chile: Editorial Universitaria.

Jocelyn-Holt, A. (2014). El Chile perplejo del avanzar sin transar al transar sin parar. Santiago, Chile: Grupo Editorial.
Kipping, M., Wadhwani, D., \& Bucheli, M. (2014). Analysing and interpreting historical sources: A basic methodology. In M. Buchelli, \& D. Wadhwami (Eds.). Organizations in time (pp. 305-329). Oxford, USA: Oxford University Press.

Kroezen, J., \& Heugens P. (2013). Organizational identity formation: Processes of identity imprinting and enactment in the Dutch microbrewing landscape. In M. Shultz, S. Maguire, A. Langley, \& H. Tsoukas (Eds.), Constructing identity in and around organizations. Oxford, USA: Oxford University Press.

Laval, E. (1938). Fundación del Hospicio de Santiago. Revista de Asistencia Social, 7(4), 412-450.

Mahoney J., \& Thelen, K. (2010). A theory of gradual institutional change. In J. Mahoney, \& K. Thelen (Eds.). Explaining institutional change (pp. 1-37). Cambridge, USA: Cambridge University Press.

Martin, J. (1992). Cultures in organizations: Three perspectives. Oxford, USA: Oxford University Press

McCabe, D. (2009). Strategy-as-power: Ambiguity, contradiction and the exercise of power in a UK building society. Organization, 17(2), 151-175. doi:10.1177/1350508409338885

Meyerson, D. (1991). Normal ambiguity: A glimpse of an occupational culture. In P. Frost, L. Moore, M. Louis, C. Lundberg, \& J. Martinet (Eds), Reframing organizational culture (pp. 131-156). New York, EUA: Sage.

Miller, E. (1983). Technology, territory and time: The internal differentiation of complex production systems. In E. Trist, \& H. Murray (Eds.). A Tavistock anthology vol. II: The socio-technical perspective (pp. 385404). Pennsylvania, EUA: The University of Pennsylvania Press.

Montauban, A. (1887). El Hospicio de Santiago. Revista Médica de Chile, 16(2), 49-109.

Moulian, T. (1997). Chile actual anatomía de un mito. Santiago, Chile: LOM Ediciones.

Ravasi, D., \& Schultz, M. (2006). Responding to organizational identity threats: Exploring the role of organizational culture. The Academy of Management Journal, 49(3), 433-458. doi:10.5465/ AMJ.2006.21794663

Ricoeur, P. (1981). Hermeneutics \& the human sciences. Cambridge, UK: Cambridge University Press.

Ricoeur, P. (2004). Memory, history and forgetting. London, UK: University of Chicago Press.

Rowlinson, M., Jacques, R., \& Booth, C. (2009). Critical management and organizational history. In M. Alvesson, T. Brigman, \& $\mathrm{H}$. Willmott (Eds.). The Oxford handbook of critical management studies (pp. 286303). Oxford, USA: Oxford University Press.

Salazar, G., \& Pinto, J. (1999). Historia contemporánea de Chile I. Santiago, Chile: LOM Ediciones.

Sanfuentes, M., \& Acuña, E. (2014). The castaways of life: A study of organizational remembering within the context of a Chilean geriatric hospital. Culture and Organization, 20(4), 288-306. doi:10.1080/14 759551.2013 .872643

Scott, R. (2014). Institutions and organizations ideas, interests, and identities. London, UK: Sage.

Selznick, P. (1957). Leadership in administration a sociological interpretation. California, EUA: University of California Press.

Silva, F. (2007). El Chile liberal y los pobres (1871-1920). Anales del Instituto de Chile, 26, 207-255. 
Suchman, M. (1995). Managing legitimacy: Strategic and institutional approaches. The Academy of Management Review, 20(3), 571-610.

Suddaby, R., Foster, W., \& Mills, A. (2014). Historical institutionalism. In M. Buchelli, \& D. Wadhwami (Eds.). Organizations in time (pp. 100123) Oxford, USA: Oxford University Press.
Walker, F. (2003). Derecho de las relaciones laborales. Santiago, Chile: Editorial Universitaria.

Weber, M. (2009). Sociología de poder. Madrid, Spain: Alianza Editorial. 